\title{
Acerca de William Walker y su relación con algunas sociedades secretas
}

\section{On William Walker and his Connections with and Some Secret Societies}

\author{
Oriester Abarca Hernández \\ Doctor en Historia, Universidad de Costa Rica. Profesor Catedrático de la Universidad de Costa Rica. Correo \\ electrónico: oriesterabarca@gmail.com
}

\section{Luz Mary Arias Alpízar}

Magister en Educación y M. Sc. en Administración de Negocios. Profesora Asociada de la Universidad de Costa Rica. Correo electrónico: luzmaryarias@gmail.com

DOI: http://dx.doi.org/10.15517/rehmlac.v7i2.22690

Fecha de recibido: 21 de agosto de 2016 - Fecha de aceptación: 17 de octubre de 2016

\section{Palabras clave}

Filibusterismo; Caballeros del Círculo Dorado; Orden de la Estrella Solitaria; Gran Logia Suprema de la Liga de la Estrella Roja de Estados Unidos

\section{Keywords}

Filibusterism; Knights of the Golden Circle; Order of the Lone Star; Supreme Grand Lodge of the League of the Red Star of the United States

\section{Resumen}

Según diversas fuentes, William Walker recibió la ayuda de sociedades secretas para sus incursiones filibusteras en Centroamérica. Se seleccionaron algunas fuentes principales para examinar algunas dimensiones del problema que se plantea en el presente artículo: ¿tuvo el proyecto de William Walker una conexión real con organizaciones secretas? Se hace énfasis en la crítica de las fuentes y los posibles intereses que yacen detrás de los hechos que narran.

\section{Abstract}

According to various sources, William Walker received the aid of secret societies for his filibustering raids in Central America. Four main sources were selected to examine some aspects of the problem addressed in this article: Did Walker's projects have a real connection with secret organizations? The emphasis is on criticism of sources and any interest that lies behind the facts stated.

\section{Introducción}

William Walker, conocido como el Rey de los filibusteros o el Predestinado de los ojos grises, fue una celebridad para algunos segmentos de la sociedad estadounidense en el segundo lustro del decenio de 1850 , periodo en el que la prensa estadounidense reportó 
ampliamente sobre él, sus acciones y conexiones. Sobre el tema también se publicaron libros, folletos y panfletos, dirigidos a influenciar la construcción del imaginario colectivo sobre Walker. Un temprano ejemplo de ello es el propagandístico libro de Welles, Walker's Expedition to Nicaragua, publicado en 1856, cuando Walker estaba en el cénit de su poder en Nicaragua ${ }^{1}$.

Las sociedades secretas formaban parte de la escena política y social estadounidense de mediados del siglo XIX, cuando "el país había sido completamente cubierto por numerosas sociedades secretas patrióticas, políticas y de otro tipo" con las que se llevaba a cabo "el negocio del país y se atendían los asuntos cotidianos de la vida"2. Es la época en que también se produjeron los movimientos filibusteros, especialmente durante el decenio de 1850. No es extraño, entonces, que los proyectos de estos fueran ligados ficticiamente a sociedades secretas, o bien, que tuvieran una conexión real con ellas.

Antes de exponer el examen del tema, una acotación conceptual preliminar es necesaria: algunas sociedades estadounidenses del siglo XIX se calificaban a sí mismas como "secretas", pero su existencia era conocida por el público y acerca de ellas la prensa informaba de manera abundante. En ocasiones, las mismas sociedades secretas ponían a disposición de los periódicos y de las empresas editoras información que era de su interés que se divulgara o realizaban actos públicos, tales como vistosas procesiones ${ }^{3}$. Su carácter secreto más bien debe entenderse como "discreción" respecto a sus verdaderos objetivos y procedimientos; estos en muchos casos resultaban ilegales y no necesariamente coincidían con los que declaraban públicamente. Pero respecto a tal secretismo no eran infalibles, pues la información sobre sus proyectos a veces se filtraba y era conocida por terceros.

El presente documento, dividido en tres secciones, discute acerca de las relaciones que algunas fuentes atribuyen a Walker con las siguientes sociedades secretas: la Orden de la Estrella Solitaria, la Orden de los Caballeros del Círculo Dorado y la Gran Logia Suprema de la Liga de la Estrella Roja, y se plantean hipótesis al respecto.

\footnotetext{
${ }^{1}$ William W. Welles, Walker's Expedition to Nicaragua: A History of the Central America War (Nueva York: Stringer and Townsend, 1856).

${ }^{2}$ Albert C. Stevens, ed., The Cyclopedia of Fraternities (Nueva York: Hamilton Printing \& Publishing Co., 1899), 284.

${ }^{3}$ Un ejemplo al respecto es la Orden de los Hijos de Malta (Sons of Malta), sociedad secreta organizada en el Sur en 1856 y que desapareció a inicios de la Guerra Civil estadounidense. Organizaban vistosas procesiones, a menudo previamente publicitadas en los periódicos, tales como la que denominaron el "Festival of the Seven Cardinals", en la que 500 de sus miembros, vestidos con armadura y ropajes y plumas de varios colores, desfilaron el 11 de octubre de 1859 por las calles de Nueva York y fueron vitoreados por el público aglomerado a lo largo de su recorrido. The New York Times, "Masquerade of the Sons of Malta", 12 de octubre de 1859, n.d. Frank Leslie's Illustrated Newspaper, "Grand Exposure of the Ceremonies of the Sons of Malta”, IX, no. 219 (1860): 161, 162, 169, 170.
} 


\section{La Orden de la Estrella Solitaria}

Según el periódico londinense The Spectator, en un artículo publicado el 17 de agosto de 1861, luego del intento de Narciso López de tomar Cuba por la fuerza ${ }^{4}$, la prensa estadounidense fue abundante en alusiones a la Orden de la Estrella Solitaria (Order of the Lone Star u O.L.S., por sus siglas), la cual, se decía, se había para conquistar Cuba y Nicaragua. The Spectator también hacía algunas aseveraciones interesantes sobre las relaciones entre la O.L.S. y las aventuras filibusteras de William Walker en Centroamérica.

Específicamente, The Spectator afirmaba que Pierre Soulé era el presidente de la O.L.S., por lo que su posterior designación, en 1853, como embajador de Estados Unidos ante España, había sido considerada por la Corte hispana como una descortesía intencional. Agregaba que también López pertenecía a la O.L.S. y que de las filas de esta, "Walker obtuvo sus más ardientes reclutas", pero que luego del fracaso de la primera expedición del "Predestinado de los Ojos Grises", la sociedad dejó de tener protagonismo; no obstante, sus miembros más violentos, ante las primeras manifestaciones de predominancia de los "Free-soilers", organizaron una sociedad secreta que denominaron la Orden de los Caballeros del Círculo Dorado (Knights of the Golden Circle o K.G.C., por sus siglas) ${ }^{6}$.

Lo anterior sugiere posibles conexiones entre Walker y ambas sociedades. La presente sección examina lo atinente a la O.L.S., dejándose para la sección subsiguiente el examen de las posibles relaciones de Walker con los K.G.C.

El primer asunto a considerar es el contexto político en que tuvo lugar la mencionada publicación. The Spectator fue comprado en diciembre de 1858 por los estadounidenses James McHenry y Benjamin Moran; su línea editorial seguía las posiciones políticas de la administración del presidente Buchanan. Cuando en enero de 1861 fue vendido, The Spectator asumió una perspectiva contraria a Buchanan y al esclavismo y, durante la Guerra de Secesión, tomó partido por la Unión. Así, en el momento en que The Spectator "informó" acerca de la conexión de Walker con la O.L.S., ese periódico ya había cambiado su posición política, Buchanan había concluido su periodo

\footnotetext{
${ }^{4}$ Narciso López invadió Cuba desde Estados Unidos en dos ocasiones. En la primera, desembarcó el 19 de mayo de 1850 en Cárdenas (Matanzas). Se segundo desembarcó fue en Playitas, al oeste de Bahía Honda (Pinar del Río) el 12 de agosto de 1851. Derrotado por las fuerzas españolas, fue condenado a la pena de muerte y ejecutado por medio del garrote vil el 1 de setiembre de 1851.

${ }^{5}$ Los Free-soilers eran los miembros y seguidores del Free Soil Party, que participó en las elecciones presidenciales de 1848 y 1852. Se oponían a la expansión del sistema esclavista a los territorios del Oeste. Sostenían que el sistema de "hombres libres" en "tierra libre" era superior, tanto desde un punto de vista moral como económico, al sistema esclavista. El Partido fue absorbido en buena medida por el Partido Republicano en el periodo 1854-1856.

${ }^{6}$ The Spectator, "The Knights of the Golden Circle", 17 de agosto de 1861, 890-891. En su edición del 30 de agosto de 1861 The New York Times también se refirió a la supuesta relación entre Walker y los K.G.C. y reprodujo el artículo publicado por The Spectator. The New York Times, "The Knights of the Golden Circle", 30 de agosto de 1861,2 .
} 
presidencial y Lincoln estaba en la Presidencia; además, la Guerra de Secesión ya había comenzado ${ }^{7}$.

La publicación de The Spectator respondía a las tácticas del gobierno republicano, en el contexto de la Guerra Civil, de atribuir a los Copperheads hechos e ideas de rebelión y traición que estos supuestamente llevaban a cabo por medio de ciertas organizaciones secretas, principalmente los K.G.C.

Como se expondrá posteriormente, no es verosímil que Walker haya pertenecido a la Orden de los K.G.C. y esta misma organización fue, en gran medida, una trama inventada primero por George W. Bickley, su fundador, para obtener recursos y notoriedad, y luego por los unionistas republicanos, para apuntalar sus esfuerzos ideológicos de guerra en contra de la posición de los Copperheads.

Los K.G.C. adquirieron notoriedad en el periodo de la Guerra de Secesión, durante el cual existieron otras organizaciones políticas secretas como los Heroes of America y the Peace Society. Durante dicho conflicto bélico los K.G.C. fueron catalogados como Copperheads, junto con los Sons of Liberty (los Hijos de la Libertad) y la Order of the American Knights (la Orden de los Caballeros Americanos).

Los Copperheads se oponían a la guerra y por tanto a las acciones militares del gobierno republicano de Lincoln. Los Hijos de la Libertad y la Orden de los Caballeros Americanos eran organizaciones políticas secretas del Partido Demócrata, que estaban pobremente dirigidas, tuvieron una corta vida y no fueron más que organizaciones en el papel. La Orden de los K.G.C. no tuvo una conexión política y fue más fantasía que realidad. Estas tres organizaciones fueron, al decir de Klement, "tigres de papel", pero en torno a ellas, por el contexto de guerra y conflicto político acérrimo en que existieron, se ha creado un mito que las representa como fuerzas políticas que buscaban constituir una Confederación Noroeste y destruir la Unión. Los relatos que la prensa y los editores ponían a circular con la intención de apoyar a la administración de Lincoln en sus actos de represión de los Copperheads luego fueron asumidos como verdad histórica ${ }^{8}$.

Uno de esos relatos, similar al artículo de The Spectator en cuanto a contenido e ideas, es el folleto K.G.C.: An Authentic Exposition of the Origin, Objects, and Secret Work of the Organization Known as the Knights of the Golden Circle, que The United States National Union Club publicó en febrero de 1862. En este opúsculo se expresa:

El leal pueblo de Estados Unidos desde hace mucho ha estado consciente de la existencia en este país, y especialmente en los estados del Sur, de varias organizaciones secretas que tienen por objeto la "americanización" de algunos de

\footnotetext{
${ }^{7}$ Se toma como fecha de inicio de la Guerra de Secesión el 12 de abril de 1861, cuando ocurrió el ataque confederado a Fort Sumter.

${ }^{8}$ Frank L. Klement, Dark Lanterns: Secret Political Societies, Conspiracies, and Treason Trials in the Civil War (Baton Rouge: Louisiana University Press, 1989), 7-33.
} 
nuestros más débiles vecinos más allá de las fronteras al sur de nuestro dominio y la expansión del poder de sus líderes y miembros por medio de la adquisición forzada de territorio y la subversión de los gobiernos de los Estados de Centroamérica y México. De este carácter fue la Orden de la Estrella Solitaria, bajo cuyos auspicios se reunieron hombres y medios para las correrías de [Narciso] López en la isla de Cuba en los años 1850 y 1851, y para las posteriores incursiones en los Estados de Centroamérica bajo el liderazgo del "predestinado de los ojos grises", William Walker.

Esta Orden de la Estrella Solitaria era una rama de aquella ahora conocida como K.G.C., si en verdad no es idéntica a ella... Un inteligente caballero, alguna vez miembro de esta organización, nos ha asegurado que en sus inicios ella no tenía planes hostiles a nuestros propios gobierno y pueblo, y que su único objeto era la adquisición de territorio extranjero por la fuerza de las armas, la introducción de migrantes llevados de los estados del Sur, quienes ocuparían y poseerían el suelo y reducirían a los nativos a la condición de esclavos, o bien, los expulsarían del país a punta de bayoneta. Estos grandes esquemas fracasaron por el momento, y los miembros que quedan de esta banda de piratas de tierra pronto encontraron trabajo en casa ${ }^{9}$.

El documento publicado por The United States National Union Club incurre en al menos dos errores. En 1850 y 1851 aún no se había creado la Orden de los K.G.C.; para muchos historiadores se creó en 1854, pero es plausible afirmar que su verdadero año de creación fue 1859. Además, la O.L.S. fue creada en 1851, luego -no antes- de la muerte de López, por John A. Quitman y otros expansionistas en Nueva Orleans y funcionaba en varias ciudades del Sur y en Nueva York, "a la manera de las logias masónicas"10. En consecuencia, la O.L.S. no podía ser una rama de los K.G.C. ni estos pudieron haber organizado las incursiones de López a Cuba. Se trata de una publicación con la que los unionistas buscaban relacionar las ideas de filibusterismo y esclavismo con la de secesionismo, para legitimar la posición pro bélica de la administración de Lincoln. Sin embargo, lo anterior no descarta la plausibilidad de la aseveración de que la O.L.S. organizó y financió las aventuras filibusteras de López y Walker.

Una fuente distinta, anterior al periodo de la Guerra Civil, afirmaba en 1852 que luego de la derrota y muerte de López, "otra conspiración cubana se está preparando. Toma la forma de una bien organizada y extendida asociación política. Se denomina la Orden de

\footnotetext{
${ }^{9}$ The United States National Union Club, K.G.C.: An Authentic Exposition of the Origin, Objects, and Secret Work of the Organization Known as the Knights of the Golden Circle (febrero de 1862 [citado el 3 de mayo de 2016]): disponible

en

https://books.google.co.cr/books?id=LPwIta1NyLgC\&pg=PA5\&lpg=PA5\&dq=knights + of + the + columbian $+\mathrm{s}$ tar\&source $=$ bl\&ots $=$ QkKieCOxSO\&sig $=$ JlxA6usU0UbxrW4KBNHuxI7B86U\&hl=es\&sa $=$ X\&redir esc $=\mathrm{y} \# \mathrm{v}$ $=$ onepage \&q=knights $\% 20$ of $\% 20$ the $\% 20$ columbian $\% 20$ star \& $\mathrm{f}=$ false

${ }^{10}$ Basil Rauch, American Interest in Cuba: 1848-1855 (Nueva York: Columbia University Press, 1948), 228.
} 
la Estrella Solitaria""1 y agregaba que en Nueva York había siete u ocho divisiones, que abarcaban varios miles de miembros comprometidos a marchar a Cuba en el momento que se les avisara. "Soldados eminentes, comerciantes, médicos, abogados, editores e incluso teólogos son miembros activos e influyentes de esta Orden, y están llenando rápidamente sus arcas con oro"12.

La misma fuente reproduciría un documento que, afirmaba, había sido elaborado por orden del Presidente-General de la O.L.S., respecto del origen, progreso y objeto de esa organización. Según este documento, debido a la muerte de López y a la represión de la insurrección "los amigos de la libertad se reunieron para adoptar las medidas necesarias para redimir las promesas de López; y la fundación de la 'Orden de la Estrella Solitaria' fue el resultado de sus deliberaciones" "13. Los resultados adversos de la invasión a Cuba significaron un punto de inflexión pues ya no se consideraba practicable o legal reiniciar la lucha por medio de una expedición estadounidense; "consecuentemente, la 'Estrella Solitaria' se dedicó a perfeccionar y expandir su organización, reuniendo todos los elementos y recursos necesarios para ayudar a todo el esclavizado pero valeroso pueblo que lance el grito de la independencia" $"$.

La Constitución de la O.L.S., siempre según la misma fuente, se adoptó en la ciudad de Lafayette en $1851^{15}$ y consistía de catorce artículos; su objeto era "la expansión del área de libertad" sin intervención militar directa. La primera división fue instituida en Nueva Orleans y para 1852 había unas cincuenta en cerca de una decena de estados de la Unión, incluida una división cubana denominada "La Unión"16 en la ciudad de Nueva York. Los miembros sumaban más de quince mil y cada uno debía contribuir con al menos tres dólares por su iniciación, cinco dólares por el segundo grado y otros cinco por el tercero,

${ }^{11}$ The Working Man's Friend and Family Instructor, "The Order of the Lone Star", III, no. 53 (1852): 10.

${ }^{12}$ The Working Man's Friend and Family Instructor, "The Order of the Lone Star", 10.

${ }^{13}$ The Working Man's Friend and Family Instructor, "The Order of the Lone Star", 10.

${ }^{14}$ The Working Man's Friend and Family Instructor, "The Order of the Lone Star", 10.

${ }^{15}$ Afirma Keehn que la O.L.S. se formó en 1851, en las oficinas del periódico pro expansionista de Nueva Orleans The Daily True Delta, por expatriados cubanos y aventureros sureños, para sacar a Cuba del dominio español y eventualmente anexarla a Estados Unidos como un territorio esclavista, y que fue en ese periódico donde se imprimió en 1851 The Constitution of the Order of the Lone Star.

Las relaciones de este periódico con la O.L.S. y con los proyectos de invasión filibustera a Cuba son claros. Lawrence J. Sigur, director del The Daily True Delta, compró el barco Pampero, a un precio de 75.000 dólares, con el que López desembarcó en Playitas, al oeste de Bahía Honda (Pinar del Río) el 12 de agosto de 1851. El capitán del Pampero -y anteriormente del Creole, barco de la fallida incursión filibustera a Cuba de 1850-, Armstrong Irvine Lewis, era miembro de la División de Nueva York de la O.L.S.

David C. Keehn, Knights of the Golden Circle: Secret Empire, Southern Secession, Civil War (Baton Rouge: Louisiana State University Press, 2013). Louis Schlesinger, "Personal Narrative of Louis Schlesinger, of Adventures in Cuba and Ceuta", Democratic Review 31, no. 168 (1852): 213. Leví Marrero, Cuba: sociedad y economía, tomo VII, Azúcar, Ilustración y conciencia (Madrid: Editorial Playor S. A., n.d.), 187-188.

${ }^{16}$ De acuerdo con Dollero: "En Broadway No. 600 (N. Y.) se reunían en La Unión (que era la División 3a. de la Estrella Solitaria) varios patriotas cubanos: fungiendo como Secretario de la Sociedad D. Francisco de Armas". Adolfo Dollero, Cultura cubana (la provincia de Pinar del Río y su evolución) (La Habana: Imprenta Seoane y Fernández, 1921), 71. 
pero se afirmaba que casi todas las divisiones habían aumentado esos montos. Finalmente, el documento citado reiteraba el compromiso de la O.L.S. de no intervención directa y su posición contraria a la anexión de Cuba a Estados Unidos.

Se trataba de un recurso retórico por parte de la O.L.S., pues su objeto era la escisión de Cuba del poder español, aunque la posición que declaraba públicamente fuese no intervenir de manera armada directamente ${ }^{17}$. La O.L.S. en el decenio de 1850 no solo fue relacionada con los intentos de anexar Cuba a Estados Unidos: también "surgió un temor durante la fiebre del oro de que Estados Unidos estaba planeando secretamente anexarse Australia por medio de la 'Orden de la Estrella Solitaria' y acreditaba a los estadounidenses el fomento de la rebelión de Eureka” de $1854^{18}$.

Jones afirma que el líder de la O.L.S. era el general John A. Quitman y su jefe militar era Ambrosio José González y que "para 1852 se planeó una nueva invasión pero no tuvo lugar, aunque 'Young Cuba' realizó muchas reuniones públicas y desfiles y publicó muchos llamamientos a los amigos de la independencia de Cuba"19. Al efecto, la O.L.S. "reclutó aventureros y trató de recaudar fondos en todas las ciudades costeras de la Unión"

La O.L.S. estaba estrechamente relacionada con el movimiento Young America. El concepto del destino manifiesto representaba la ideología de este movimiento, el cual era una coalición de políticos, periodistas y hombres de negocios ubicados en el seno del Partido Demócrata, aunque no era un grupo formalmente constituido. Young America buscaba unir todos los segmentos de la nación por medio de un nacionalismo romántico, propugnaba el libre comercio, una marina mercante subsidiada, el expansionismo del imperio estadounidense por medios tanto públicos como privados, la abolición de la ley de neutralidad de 1818 (lo que permitiría legalizar el filibusterismo) y un apoyo activo a los republicanos europeos. A Young America pertenecieron personajes influyentes como John O'Sullivan, Pierre Soulé y George N. Sanders.

La ideología del destino manifiesto surgió en coincidencia con los levantamientos pro republicanos en Europa, lo que reforzó 'la creencia de que el 'joven' Estados Unidos era un modelo para reformar el Viejo Mundo"21. Pero también afianzó las ideas de los miembros del movimiento Young America de expandir las instituciones estadounidenses al resto del continente americano. Las ideas de filósofos como Emerson y Thoreau y de

\footnotetext{
${ }^{17}$ Véase al respecto The United States Democratic Review, "The Order of the Lone Star", 32, no. 1 (1853): 80-85.

18 James Dahlstrom, "America, the Forbidden Fruit: Anti-American Sentiment in 'Robbery under Arms"”, Antipodes 25, no. 2 (2011): 146; White, "The United States in the 1850's", 529.

${ }^{19}$ Lewis P. Jones, “Ambrosio José Gonzales, a Cuban Patriot in Carolina”, The South Carolina Historical Magazine 56, no. 2 (1955): 69.

${ }^{20}$ Horace Greely, The American Conflict: A History of the Great Rebellion in the United States of America, 1860-'64, vol. 1 (Chicago: Geo. \& C. W. Sherwood, 1865), 270.

${ }^{21}$ Walter L. Hixson, American Foreign Relations. A Diplomatic History (Nueva York y Londres: Routledge, 2016), 70 .
} 
literatos como Melville sirvieron de fundamento ideológico para la práctica del filibusterismo y especialmente para justificar las expediciones de Narciso López con las que se buscaba anexionar Cuba a Estados Unidos.

Uno de los mayores líderes de Young America fue O'Sullivan. Este consideraba que la política y la literatura estaban íntimamente relacionadas. Por ello creó, con el padrinazgo de Martin van Buren, la revista The United States Magazine and Democratic Review, también conocida como Democratic Review ${ }^{22}$, de la cual era editor. En un artículo publicado en dicha revista en 1845, O'Sullivan creó el concepto de "destino manifiesto",23, que sirvió de lema al movimiento Young America y adquirió amplia notoriedad posteriormente. Los estadounidenses eran así "men of destiny" que podían y debían construir un imperio y "regenerar" aquellas regiones que consideraran de su apetencia, trasplantando a ellas sus instituciones. En la causa filibustera de López, según Chaffin, al menos dos periodistas del Norte, O’Sullivan y Moses Beach (del New York Sun) fueron más allá de solo escribir editoriales que la apoyaban para asumir un activo involucramiento. O'Sullivan actuó como reclutador y agente administrador de la conspiración, por lo que fue procesado dos veces, aunque sobreseído de la acusación de violar la Neutrality Act de $1818^{24}$.

En 1852 la O.L.S. apoyó a Franklin Pierce en su candidatura a la Presidencia de Estados Unidos ${ }^{25}$. Cuando este asumió el cargo, figuras notables del movimiento Young America (como Soulé, O’Sullivan y Sanders), fueron retribuidos con cargos diplomáticos en Europa, desde donde intentaron dar impulso a sus proyectos anexionistas. Young America representaba políticamente a la O.L.S. ${ }^{26}$ y, por la identidad de actores y propósitos, la O.L.S. era el ala secreta de dicho movimiento respecto a tales proyectos.

Según Rauch, la O.L.S. entonces devino un centro para organizar otra invasión a Cuba. Uno de los miembros del movimiento Young America, el banquero August Belmont, había prestado su apoyo a la candidatura de Pierce y esperaba que se realizara la compra de Cuba a España para que esta pudiera liquidar cierta cantidad de bonos insolutos. El movimiento Young America dominó a Pierce y su diplomacia durante un breve tiempo; pero esa influencia empezó a decaer a finales de mayo de 1854, cuando Pierce firmó la Kansas-Nebraska Act y emitió una proclama en contra del filibusterismo. Luego del Ostend Manifesto, de 15 de octubre de 1854 -en el que sus autores, Pierre Soulé, James Buchanan

\footnotetext{
${ }^{22}$ Los volúmenes publicados por la revista The United States Magazine and Democratic Review desde 1837 hasta 1859 pueden consultarse en http://ebooks.library.cornell.edu/u/usde/usde.html

${ }^{23}$ O'Sullivan en ese artículo elogiaba la anexión de Texas por parte de Estados Unidos y abogaba por la expansión hacia Oregón, California, Cuba y América Latina. John O'Sullivan, "Annexation”, United States Magazine and Democratic Review 17, no. 85 (1845): 5-10.

${ }^{24}$ Tom Chaffin, “'Sons of Washington': Narciso López, Filibustering, and U.S. Nationalism, 1848-1851", Journal of the Early Republic 15, no. 1 (1995): 89

${ }^{25}$ Greely, The American Conflict, 270.

${ }^{26}$ Charles H. Brown, Agents of Manifest Destiny: The Lives and Times of the Filibusters (Chapel Hill: University of North Carolina Press, 1980).
} 
y John Y. Mason, propugnaban los intereses de los estados del Sur para la anexión de Cuba a Estados Unidos, incluso por la fuerza-, el Secretario de Estado William L. Marcy repudió, el 13 de noviembre de 1854, a los diplomáticos del movimiento Young America ${ }^{27}$.

El cónsul inglés en Galveston, Arthur T. Lynn, reconocía el objeto expansionista de la O.L.S. Afirmaba que en 1854 la O.L.S. estaba compuesta en el Oeste por varios miles de miembros que se autodenominaban filibusteros. Según Lynn, "el principio público de esta Asociación es 'extender el área de la libertad', pero el verdadero y reconocido motivo es la especulación mercenaria de los beneficios que podrían surgir de la confiscación de latifundios mediante el desmembramiento de Cuba o de porciones de México, y es esta sociedad la que ha organizado las expediciones hostiles contra estos países" ${ }^{\text {,28 }}$.

La pérdida de la influencia diplomática de Young America supuso también la pronta declinación de la O.L.S. hasta desaparecer ${ }^{29}$. Sin embargo, aún se planeó otra expedición filibustera a Cuba para 1855. De nuevo, su líder sería Quitman, quien había sido nombrado el 18 de agosto de 1853, por la anexionista Junta Cubana de Nueva York (de la cual John O’Sullivan era miembro), Jefe Civil y Militar de la Revolución y se le había ofrecido un millón de dólares en caso de lograrse el triunfo ${ }^{30}$. Entonces, la O.L.S. "con sus logias subordinadas llevaron a cabo los preparativos necesarios sin levantar sospecha. La obligación de secreto impuesta a los iniciados prevenía la publicación de detalles"31 . Según el Capitán General de Cuba, José de la Concha, "el desembarco había de coincidir con un levantamiento en el país en los primeros meses de $1855^{\prime 32}$. Pero la planeada incursión finalmente no tuvo lugar. Quitman fue convocado a Washington, donde altos funcionarios le informaron acerca de la posición del gobierno de Pierce, contraria a la invasión de Cuba. En consecuencia, Quitman renunció ante la Junta Cubana el 30 de abril de $1855^{33}$. Aunque esto supuso el fin del movimiento anexionista cubano, no significó el fin de las empresas filibusteras ni la participación de otros miembros de la O.L.S., como Pierre Soulé, en ellas.

Soulé fue una figura central en el movimiento Young America y en la O.L.S. De esta última, según The Spectator, era el presidente. Soulé fue Senador por Luisiana (1849-1853) y representante diplomático de Estados Unidos ante España (1853-1855). Ampliamente conocido como uno de los autores del Ostend Manifesto, su posición expansionista era clara y colaboró de diversos modos con Walker y su proyecto filibustero en Nicaragua, una vez

\footnotetext{
${ }^{27}$ Rauch, American Interest in Cuba.

${ }^{28}$ Laura A. White, “The United States in the 1850's as Seen by British Consuls", The Mississippi Valley Historical Review 19, no. 4 (1933): 529.

${ }^{29}$ Literalmente "subsided into nothingness". Greely, The American Conflict, 270.

${ }^{30}$ J. F. H. Claiborne, Life and Correspondence of John A. Quitman, vol. II (Nueva York: Harper \& Brother, 1860), 389 y 390.

${ }^{31}$ Earl W. Fornell, “Texans and Filibusters in the 1850's”, The Southwestern Historical Quarterly 59, no. 4 (1956): 413.

32 José de la Concha, Memoria dirigida al Excmo. Sr. don Francisco Serrano y Domínguez (Madrid: Imprenta de La Reforma, 1867), 9.

${ }^{33}$ Claiborne, Life and Correspondence of John A. Quitman, vol. II, 392.
} 
que habían resultado fallidos los diversos intentos filibusteros de tomar $\mathrm{Cuba}^{34}$. En una carta dirigida a los editores del New Orleans Daily Crescent, publicada por este periódico el 11 de diciembre de 1858, un autor, identificado con el pseudónimo de Syphax, expresaba que "Soulé era el santo patrón del general Walker"35.

Varios hechos confirman la participación de Soulé en las aventuras filibusteras de Walker en Nicaragua. Por ejemplo, mediante una carta suscrita en Nueva Orleans el 17 de abril de 1856, varios ciudadanos de esa ciudad, considerando la importancia que los hechos que estaban ocurriendo en Centroamérica tenían para Estados Unidos y "especialmente para los intereses del Sur" y que era un "momento crítico que exigía una pronta y enérgica acción", le solicitaron a Soulé una reunión para que les expusiera la información que poseyera y les brindara las sugerencias que estimara convenientes. Soulé respondió, mediante una carta del 24 de abril de 1856, que estaba totalmente desconectado de las tramas y suerte del "galante aventurero", pero que había seguido con interés su carrera y “quizás simpatizado profundamente con sus aspiraciones" y aceptó la reunión ${ }^{36}$.

En Luisiana, según informaba el Southern Sentinel el 10 de mayo de 1856, se había recolectado dinero con éxito para el ejército de Walker. Entre los contribuyentes el periódico mencionaba al coronel S. F. Slatter (que aportó \$500) y a otros como Pierre Soulé y H. M. Hyams, quienes habían "aportado bonitas sumas"37.

Algunos meses después Soulé partió para Nicaragua, a encontrarse con Walker. Llegó a Granada el 20 de agosto de 1856 con el propósito de coordinar asuntos legales relacionados con el mercadeo y venta de una emisión de bonos autorizada por parte del gobierno de Walker. Los títulos serían garantizados con tierras públicas de Nicaragua y, según un decreto de 28 de agosto de 1856, serían redimibles en oro o plata del Banco de Luisiana a un plazo de veinte años ${ }^{38}$.

También por influencia de Soulé, Walker promulgó un decreto (de 22 de setiembre de 1856) que abría la vía a la reintroducción de la esclavitud en ese país ${ }^{39}$. Soulé había invertido mucho dinero en la causa de Walker, pero también había recibido beneficios, entre ellos, una hacienda en Nicaragua como premio por su colaboración en la redacción de este decreto $^{40}$.

\footnotetext{
34 J. Preston Moore, "Pierre Soulé: Southern Expansionist and Promoter", The Journal of Southern History 21, no. 2 (1995): 207-210.

35 Syphax, "Louisiana Correspondence", New Orleans Daily Crescent, 11 de diciembre de 1858, 2.

${ }^{36}$ The New York Herald, "The Hon. Pierre Soulé and the Question of the Central America", 3 de mayo de $1856,1$.

${ }^{37}$ Southern Sentinel, "Reinforcements for Walker", 10 de mayo de 1856, 3.

${ }^{38}$ Moore, "Pierre Soulé", 212.

39 John Hope Franklin, The Militant South 1800-1861 (Urbana y Chicago: University of Illinois Press, 2002), 119.

${ }^{40}$ Según el coronel filibustero William Kissane Rogers, uno de los dieciséis oficiales de Walker que se rindieron en Rivas el 1 de mayo de 1857 ante el capitán estadounidense Charles H. Davis: "Soulé, una vez le dijo a Walker: 'la mayor ayuda que usted obtiene es del Sur; usted debería demostrar de alguna manera que
} 
A inicios de 1857 el Daily Alta California informaba que "los amigos de Walker en Nueva Orleans están redoblando sus esfuerzos para enviarle ayuda"41 y "se dice que grandes mítines se han llevado a cabo en Nueva Orleans con el mismo propósito, y que 500 hombres ya están listos, armados y aprovisionados para empezar de una vez por Nicaragua y que entre 1.000 y 1.500 más los seguirían inmediatamente, bajo el mando de Soulé"42. No obstante, cabe aclarar que Soulé nunca estuvo a cargo de ningún contingente militar.

Posteriormente, cuando Walker fue indiciado en 1858 por la violación a la ley de neutralidad de 20 de abril de 1818, su defensa legal estuvo a cargo de Soulé. El compromiso de Soulé con Walker, así como del ya mencionado Slatter, puede valorarse según las acciones que realizaron en su defensa:

Cuando Walker fue arrestado [acusado de violar la ley de neutralidad de 1818] y su fianza se estableció en la suma de dos mil dólares para que compareciese ante la Corte Federal de Nueva Orleans, el coronel Slatter, un rico solterón de la ciudad, la pagó. Slatter es el dueño del City Hotel, y de New Orleans Arcade, dos casas que alquila a un precio aproximado a los cuarenta mil dólares. Ha invertido cuarenta mil dólares en la empresa de Nicaragua y ha sido amigo de Walker todo el tiempo. El ex senador Soulé también ha realizado grandes inversiones en Centroamérica y ambos

protegerá a los esclavos (sic). Promulgue un decreto que establezca que toda propiedad será protegida, que será protegida en otro lugar'. Walker desde el inicio estaba opuesto a publicar cualquier decreto que restableciera la esclavitud, pero Soulé insistió tanto que Walker finalmente cedió. Un día Walker me dijo: 'Debemos tener formuladas algunas oportunas leyes. El código de Luisiana se aproxima a lo que sería adecuado para Nicaragua'. A ninguno de los oficiales del ejército le parecía eso. Creíamos que no podríamos controlar a los 'niggars'. Había muchos mestizos y 'niggars' en el país. El resultado fue que Walker aprobó el decreto, restableciendo la esclavitud, el cual en el mejor de los casos fue un decreto en el papel y lo publicó por sugerencia de Soulé. El decreto fue considerado por Soulé como una ayuda para Walker, pero luego resultó ser en todo sentido un mal. Todos los abolicionistas empezaron a oler ratas. No había nada en él. Se usó como un gran garrote en contra de Walker. Era todo un error. La esclavitud nunca podría haber sido introducida en Nicaragua. Walker le obsequió una hacienda a Soulé por haberlo ayudado a redactar el decreto". William K. Rogers, en Albert Lagerstedt, "The Political Career of William Walker" (Tesis de Maestría, Universidad de California, 1913), n.d.

Afirma Lagerstedt, "el 22 de setiembre de 1856 Walker promulgó un decreto que restablecía la esclavitud. El resultado fue la protesta en Nicaragua, Estados Unidos e Inglaterra. Llegó a ser un relato común que el objetivo final de Walker era abrir el mercado de esclavos, lo cual no era cierto. Puesto que el sentimiento abolicionista en los Estados Unidos se levantó en su contra, ello contribuyó a que perdiera el apoyo del débil y vacilante gobierno del presidente Buchanan, el cual estaba dispuesto a sacrificar a Walker en aras del prestigio político... los enemigos de Walker obtuvieron un capital político de su acción y pronto llegó a ser un asunto de opinión común que el propósito de Walker era establecer la esclavitud en Nicaragua y así ayudar a generar para los estados esclavistas un incremento de territorio. Todo esto no tenía ningún fundamento. El propósito de Walker en Nicaragua no era el restablecimiento de la esclavitud sino unificar no solo los Estados centroamericanos sino eventualmente México también, en un imperio basado en el dominio angloamericano con él mismo a la cabeza como dictador". Lagerstedt, "The Political Career of William Walker", n.d.

Según el periódico de Walker, El Nicaragüense, en su edición del 30 de agosto de 1856, la hacienda denominada Mercedes, fue vendida a Soulé por US\$ 50.000. Moore, "Pierre Soulé", 214. Véase también The New York Times, "Hon. Pierre Soulé Hacienda", 30 de marzo de 1857, 1.

${ }^{41}$ Daily Alta California, "Nicaragua Matters", 16 de enero de 1857, 1.

${ }^{42}$ Daily Alta California, "The Meeting in New York on Saturday Night", 16 de enero de 1857, 1. 
hombres fueron ante Buchanan, con Walker, y lo escucharon prometerle a Walker que no lo interrumpiría en su expedición. Walker exige que se le juzgue y ambos serán testigos y jurarán esto en la Corte Federal"43.

El 2 de junio de 1858 el Gran Jurado deliberó pero no logró ponerse de acuerdo respecto del veredicto: diez miembros se pronunciaron por la inocencia y dos por la culpabilidad de Walker y de los demás acusados; ante esto, Walker, por intermedio de Soulé, demandó que se realizara inmediatamente un nuevo juicio, pero al día siguiente el Fiscal de Distrito desistió de la causa ${ }^{44}$.

Una vez sobreseído Walker, los planes de invasión filibustera a Nicaragua continuaron. En octubre de 1858 un despacho, emitido en Washington para The New York Herald, afirmaba que Walker y Soulé estaban construyendo una nueva trama para ubicar emigrantes en Nicaragua, que en el Sur ya se habían formado sociedades similares a las "New England Emigrant Societies" "45 y que varios grupos de emigrantes partirían de puertos sureños a principios de noviembre de $1858^{46}$. El tercer intento de Walker de tomar Nicaragua falló a finales de 1858 al naufragar la embarcación Susan.

Un punto a destacar, más allá de figuras políticas como Quitman o Soulé, es el de los oficiales que participaron en los proyectos de López y que luego se unieron a la causa de Walker en Centroamérica. Una de esas figuras fue Callender I. Fayssoux, uno de los más leales seguidores de Walker y quien había tenido una participación destacada en la incursión a Cuba, en mayo de 1850 , de Narciso López ${ }^{47}$ y luego fue el primer oficial del

\footnotetext{
${ }^{43}$ The Prairie News, "Parson Brownlow on the Walker Developments", 11 de marzo de 1858, 2. La cursiva es del original.

${ }^{44}$ William O. Scroggs, Filibusters and Financiers: The Story of William Walker and His Associates (New York: The Macmillan Company, 1916): 368-369.

45 "The New England Emigrant Societies" alude a la New England Emigrant Aid Company, establecida originalmente con el nombre de Massachusetts Emigrant Aid Company, en 1854. Su objetivo era trasladar colonos yankees al Territorio de Kansas, en el contexto de la Kansas-Nebraska Act de 1854. Esta creó la noción de soberanía popular de acuerdo con la cual los residentes votantes en ese Territorio determinarían si el futuro estado permitiría o prohibiría la esclavitud al integrarse a la Unión. Una consecuencia de la KansasNebraska Act fue, en la práctica, la abolición del Compromiso de 1820. Tanto los sureños esclavistas como los antiesclavistas del norte tenían interés en lograr un resultado demográfico favorable a sus respectivas pretensiones políticas. Nicole Etchenson, Bleeding Kansas: Contested Liberty in the Civil War Era (Lawrence: University Press of Kansas, 2004). Samuel A. Johnson, "The Genesis of the New England Emigrant Aid Company", The New England Quarterly 3, no. 1 (1930): 95-122.

${ }^{46}$ Green Mountain Freeman, "Washington Matters", 28 de octubre de 1858, 3. The Burlington Free Press, 29 de octubre de 1858, 3.

${ }^{47}$ Lorenzo Montúfar, Reseña histórica de Centroamérica, tomo VII (Guatemala: Tipografía La Unión, 1887), 488; Frederic Rosengarten Jr., William Walker y el ocaso del filibusterismo (Tegucigalpa: Guaymuras, 2002), 34; Herminio Portell Vilá, Narciso López y su época (1848-1850) (La Habana: Compañía Editora O’Reilly, 1952), 307.

En el envés de un permiso emitido por el gobernador de La Habana para que Fayssoux visitara esa ciudad el 10 de diciembre de 1859, este escribió: "Pude haber sido ahorcado o muerto a garrote si me hubieran reconocido. Al visitar La Habana, corrí un riesgo, pues había estado al servicio del general López. C. I. Fayssoux". Tulane University of Louisiana, An Inventory of the Manuscript Collections of the Department of
} 
barco Pampero ${ }^{48}$, en la incursión de agosto de 1851. Otras figuras que también participaron tanto en Cuba como en Nicaragua fueron Chatham Roberdeau Wheat, Henry Theodore Titus, Achilles L. Kewen, Louis Schlesinger y Robert Ellis ${ }^{49}$, lo que podría agregar elementos a favor de la tesis de The Spectator acerca de que Walker obtuvo de las filas de la O.L.S. "sus más ardientes reclutas".

De acuerdo con los elementos expuestos, resulta plausible plantear como hipótesis que existieron conexiones reales entre la Orden de la Estrella Solitaria o sus miembros y William Walker.

\section{La Orden de los Caballeros del Círculo Dorado}

Se ha ligado a la O.L.S. con los K.G.C. y a estos con Walker. Keehn ha planteado, aunque dentro de los términos de la historiografía estadounidense tradicional, una hipótesis que postula que el repentino poder y el prestigio que la sociedad de los K.G.C. adquirió se derivó de su fusión con la O.L.S., porque esta tenía más de 15 mil miembros y al menos 15 capítulos diseminados por los estados del Sur, con grandes concentraciones en Mississippi, Luisiana, Texas y Alabama; además, la O.L.S. contaba con capítulos en ciudades portuarias del Norte como Baltimore y Nueva York; en esta última ciudad, tenía su base de operaciones en Tammany Hall y el Empire Club ${ }^{50}$. Los K.G.C., en la versión de Keehn, fueron continuadores de la O.L.S.

Por su parte James M. Hiatt afirmó en 1861, en An Authentic Exposition of the " $K$. G. C." "Knights of the Golden Circle"; Or; A History of Secession from 1834 to $1861^{51}$, que Walker era miembro de la Orden de los Caballeros del Círculo Dorado y que esta fue creada a mediados del decenio de 1850 por George W. Bickley a partir de los Southern Rights Clubs, los que describe como sociedades secretas constituidas en Charleston y otras ciudades sureñas, para restablecer el comercio de esclavos africanos y la adquisición de nuevos territorios esclavistas.

Middle American Research. No. 1 Callender I. Fayssoux Collection of William Walker Papers (New Orleans: Tulane University of Louisiana, 1937), 16.

Sobre los intentos de López de tomar Cuba para los estados del Sur, véase: The New York Herald, "Conspiracy of Lopez in Cuba", 10 de febrero de 1858, 2. The New York Herald, "First Attempt of Lopez from This Country", 10 de febrero de 1858, 2. The New York Herald, "Last Expedition and Death of Lopez", 10 de febrero de $1858,2$.

${ }^{48}$ Schlesinger, "Personal Narrative", 215.

${ }^{49}$ Patrick Boman, Boulevard de la flibuste: Nicaragua 1850-1860 (París: Ginkgo éditeur, 2007). Nashville Union and American, "The Movements", 2. Chaffin, "Sons of Washington", 92.

${ }^{50}$ Keehn, Knights of the Golden Circle.

51 James M. Hiatt, An Authentic Exposition of the "K. G. C." "Knights of the Golden Circle”; Or, A History of Secession from 1834 to 1861 (Indianápolis: C. O. Perrine Publisher, 1861).

El folleto se publicó como anónimo, pero, según Klement, Hiatt es su autor. Klement, Dark Lanterns, 14. 
La Orden de los K.G.C. tenía, siempre según Hiatt, un objetivo similar: impulsar los intereses de los estados del Sur, lo cual suponía no solo la oposición a la abolición de la esclavitud, sino también la expansión territorial de tales estados y, de ser necesario, el establecimiento de una confederación sureña soberana. De acuerdo con Hiatt, la sociedad de los K.G.C. estaba impaciente por la lentitud del gobierno estadounidense en la adquisición de nuevos territorios, por lo que sus miembros liberales decidieron apoyar a Walker con barcos, hombres y dinero, para que tomara Nicaragua; y luego, cuando Buchanan ascendió a la presidencia de Estados Unidos, "las expediciones de Walker fueron renovadas con aumentada energía". Afirma Hiatt que cuando él escribió su "exposición" (esto es, en 1861 o antes), la Orden era exigua respecto a su número de miembros, pero entre estos se contaban muchos de los más ricos capitalistas del Sur ${ }^{52}$.

Si Walker era, como sostiene Hiatt, miembro de la Orden de los Caballeros del Círculo Dorado, ello supondría que no era el comandante en jefe sino un subordinado del líder de esa organización, G. W. Bickley, quien aunque se había autodenominado "General", desde el punto de vista militar nunca llevó a cabo ninguna acción y las únicas dos que convocó terminaron siendo rotundos fracasos, en el mejor de los casos, cuando no meros fraudes.

Muchos historiadores afirman que la Orden de los K.G.C. fue creada en 1854 en Lexington, Kentucky, por Bickley y algunas otras personas que este convocó. Este dato presenta un problema respecto a su veracidad. En primer lugar, la organización no fue conocida por el público sino hasta junio de 1859, cuando The New York Daily Tribune publicó un artículo sobre ella ${ }^{53}$ en que sostenía que sus creadores parecían haber adoptado las ideas y el sistema de las logias de los Know Nothing. Estos eran el "ala secreta" del American Party.

El movimiento Know Nothing funcionaba de manera descentralizada y con cierto grado de secretismo; se calificaba como nativista. Su "nativismo" no se refería a la defensa de los pobladores indígenas sino a la de los descendientes de los colonos protestantes y anglosajones. En consecuencia, se oponía a la inmigración de europeos católicos, especialmente irlandeses y alemanes, a los que acusaba de estar contralados por el Papa y en oposición a los valores estadounidenses. Abogaba, además, por la negación del derecho de voto a las personas nacidas fuera de Estados Unidos y su exclusión de cargos públicos. El movimiento nació en el decenio de 1840 y tuvo cierto grado de éxito en el siguiente. En 1849 se organizó como la secreta Order of the Star-Spangled Banner, en la ciudad de Nueva York, y pronto se formaron logias en casi todas las principales ciudades de Estados Unidos. Durante el decenio de 1850 fue dejando de lado su carácter secreto y se organizó como el American Party. Muchos de sus seguidores no eran más que trabajadores o

\footnotetext{
${ }^{52}$ Hiatt, An Authentic Exposition of the "K. G. C.", 10.

${ }^{53}$ The New York Daily Tribune, "K.G.C.”, 13 de junio de 1859, 4.
} 
granjeros que consideraban a los inmigrantes un peligro para sus puestos de trabajo y cultura. El último candidato presidencial del American Party, Millard Filmore, resultó vencido en las elecciones de 1856. Cuando el partido se dividió ese mismo año, muchos de sus miembros pro esclavistas se unieron al Partido Demócrata. Para 1859 la influencia del American Party casi había desaparecido y en 1860 dejó de existir pues se fundió con el Constitutional Union Party. Los Know Nothing eran expansionistas; por ello, algunos de sus miembros apoyaron las acciones imperialistas de Walker en Centroamérica.

Luego de la publicación inicial de The New York Daily Tribune, la Orden de los K.G.C., a pesar de ser una sociedad supuestamente secreta, obtuvo muy buena cobertura en la prensa, en parte por las propias diligencias de Bickley.

Es cierto que existió una conexión entre Walker y seguidores del movimiento Know Nothing, como ha expuesto Bolaños Geyer ${ }^{54}$; sin embargo, ello no es evidencia de que haya existido una conexión entre los K.G.C. y Walker. Ahora bien, si los K.G.C. apoyaron a Walker, eso solo pudo haber ocurrido en 1860, en la última correría de este a las Islas de la Bahía (Honduras), pues la Orden no existió antes de 1859. La versión de que fue creada el 4 de julio de 1854 tiene como origen la memoria de una convención de la propia organización, realizada en 1860 por convocatoria del mismo Beckley, de modo que el dato no es confiable, además de que no se puede triangular con otras fuentes.

Dicha convención se originó como una reacción de Beckley a las acusaciones que en su contra lanzaron algunos de sus propios seguidores. En la primavera de 1860 Bickley convocó a miembros de la orden a reunirse en Río Grande para invadir México; él aparecería con una gran fuerza que afirmaba habían formado en Nueva Orleans, pero Bickley nunca llegó. Esto motivó a un grupo de sus adeptos en Nueva Orleans a acusarlo de ser un líder mentiroso, inepto y cobarde. La respuesta de Bickley fue convocar una convención de la orden, la cual tuvo lugar en Raleigh (Carolina del Norte) entre el 7 y el 11 de mayo de 1860; esta lo confirmó como líder. Luego Bickley convocó a una segunda invasión de México, la cual iniciaría desde la ribera sur del Río Nueces (Condado del Encinal, Texas) el 15 de setiembre de 1860. Tampoco esta segunda acción se llevó a cabo, por falta de fondos y de seguidores. Después de esto, Bickley centró su discurso en los temas de secesión y de defensa de los derechos del Sur, dejando de lado sus "planes" filibusteros $^{55}$.

De manera que no es verosímil que una organización fallida en sus declarados propósitos expansionistas y sin recursos, ayudara a Walker. El ya mencionado Arthur T. Lynn, cónsul inglés en Galveston, en 1860 expresaba que había aparecido una nueva

\footnotetext{
${ }^{54}$ Alejandro Bolaños Geyer, William Walker, el Predestinado de los Ojos Grises (San Charles, Missouri: impresión privada, 1995), 188-208.

55 Diario de la Marina, 7 de agosto de 1860, 3. Diario de la Marina, 10 de agosto de 1860, 2. Ollinger Crenshaw, "The Knights of the Golden Circle: The Career of George Bickley", The American Historical Review 47, no. 1 (1941): 23-50.
} 
organización expansionista en el estado de Texas, la Orden de los K.G.C., pero que esta no tenía relación directa con las expediciones dirigidas por Walker ${ }^{56}$.

Mucho de lo que la prensa afirmaba sobre los K.G.C. era mera ficción que, intencionalmente o no, los ligaban al movimiento secesionista. Por ejemplo, cuando en 1861 el editor del Ohio State Journal se vio presionado ante un Gran Jurado para que explicara las contradicciones entre los rumores que su periódico había publicado respecto a la supuesta relación entre los K.G.C. y el Partido Demócrata, en la coyuntura previa a las elecciones presidenciales estadounidenses de 1860, admitió que no tenía evidencia qué ofrecer y dio una simple explicación: "como editor, él era libre de hacer acusaciones e imprimir rumores; como testigo, estaba bajo juramento de decir la verdad" ${ }^{\text {"57 }}$. Sin embargo, tales rumores periodísticos, tomados como datos, sin considerar el contexto en que se produjeron y los intereses políticos en juego, han entrado a la mainstream historiográfica estadounidense como válidos. Klement sostiene que los republicanos crearon el mito de la conspiración de las sociedades secretas de los demócratas y de los K.G.C. y las etiquetaron de organizaciones traidoras; el mito fue asumido acríticamente por los historiadores y pasó a formar parte de la historia oficial ${ }^{58}$.

La prensa también publicaba ficciones sobre Walker y sus supuestas relaciones con sociedades secretas. Solo para mencionar un ejemplo: The Yazoo Democrat, en su edición del 7 de abril de 1860, publicó un artículo apologético de los Sons of Malta en el que criticaba un "libro obsceno" que describía a esa Orden y que el periódico calificaba de falso. El artículo además señalaba que se trataba de un "ardid yankee" "59. De seguido, en la misma columna, The Yazoo Democrat publicó otro artículo en el que informaba que los Sons of Malta habían realizado una procesión de unas 300 personas, "conducida por tres oficiales a caballo": el general Garibaldi ("quien ha sido por mucho tiempo miembro de la Orden"), Víctor Manuel II, rey de Italia ("quien también es un honorable miembro de la Orden") y el general William Walker ${ }^{60}$.

En consecuencia, An Authentic Exposition of the "K. G. C." formó parte de la táctica republicana de ligar a los K.G.C. con el secesionismo de los confederados. Al relacionar a Walker con los K.G.C. también se calificaba a los Copperheads de filibusteros, esclavistas y secesionistas, que merecían ser reprimidos por la administración federal.

En todo caso, no parece posible que Walker haya formado parte de los K.G.C. ni que haya recibido financiamiento o cualquier otro tipo de ayuda de Bickley o de la orden

\footnotetext{
${ }^{56}$ Citado en Fornell, "Texans and Filibusters in the 1850's", 427.

${ }^{57}$ Klement, Dark Lanterns, 16.

${ }^{58}$ Frank L. Klement, "Copperhead Secret Societies: In Illinois during the Civil War", Journal of the Illinois State Historical Society 48, no. 2 (1955): 152-180; "Carrington and the Golden Circle Legend in Indiana during the Civil War", Indiana Magazine of History 61, no. 1 (1965): 31-52; "Catholics as Copperheads during the Civil War", The Catholic Historical Review 80, no. 1 (1994): 36-57.

${ }^{59}$ The Yazoo Democrat, "I.O.S.M.", 7 de abril de 1860, 2.

${ }^{60}$ The Yazoo Democrat, 7 de abril de 1860, 2
} 
cuya creación a este se atribuye. Una situación distinta se presenta respecto a la Gran Logia Suprema de la Liga de la Estrella Roja de Estados Unidos.

\section{La Gran Logia Suprema de la Liga de la Estrella Roja}

En su última correría por Centroamérica, William Walker atacó el puerto de Trujillo (Honduras) el 6 de agosto de 1860. Derrotado, se rindió ante Nowell Salmon (oficial al mando de la fragata de guerra británica Icarus), quien lo entregó a las autoridades hondureñas ${ }^{61}$.

Un mes después, el 6 de setiembre de 1860, el general Norberto Martínez, en la Comandancia Principal de Trujillo, ordenó que se abriese un proceso en contra de Walker $^{62}$. Interrogado este acerca de quién lo había auxiliado para llevar a cabo esa expedición, respondió, según Mayes Huete, que

...varias personas de los Estados Unidos, que corresponden a un partido político creado en los E.E. U.U. y que lleva el nombre de: DERECHOS DE LOS ESTADOS DEL SUR, y al que pertenecen cientos de miles de ciudadanos, y que el partido tiene los fines de la constitución de la Gran Logia ESTRELLA ROJA (esta sociedad era con el objeto de defender la esclavitud, donde estuviera establecida, fomentarla y extenderla donde fuera posible) ${ }^{63}$.

Existen diversos elementos que sugieren que sí existió una conexión entre Walker y la mencionada Gran Logia Suprema de la Liga de la Estrella Roja. En primer lugar, entre los documentos personales que se le incautaron en Trujillo constaba un libro impreso con el título Constitución y leyes accesorias de la Gran Logia Suprema de la Liga de la Estrella

${ }^{61}$ Regis A. Courtemanche, "The Royal Navy and the End of William Walker", The Historian 30, no. 3 (1968): 350-365.

${ }^{62}$ Diario de la Marina, "Fusilamiento de Walker", 26 de setiembre de 1860, 3.

${ }^{63}$ Guillermo Mayes Huete, Campaña nacional centroamericana contra los filibusteros en Nicaragua, 18561956 (Tegucigalpa: Ministerio de Educación Pública, 1956), 41-42. Las mayúsculas aparecen en el original.

El hondureño Cáceres Lara presenta otra versión de lo declarado por Walker, quien “....esperaba recibir en Trujillo los refuerzos que le llegarían, los cuales le eran proporcionados por un partido político a crearse en los Estados del Sur de los Estados Unidos que llevaría por nombre 'Derechos de los Estados del Sur' el cual guardaba armonía con la Gran Logia 'Red Star' de cuya constitución las tropas hondureñas habían capturado ejemplares en manos de los filibusteros”. Esta fuente presenta un problema respecto del orden temporal de los hechos: no es razonable que Walker se lanzara a una aventura riesgosa y que requería de significativos recursos materiales y humanos, esperando que estos fueran proveídos por una organización que aún no se había formado. Víctor Cáceres Lara, "La aventura postrera de William Walker en Honduras", Revista Conservadora 10, no. 52 (1965), 50.

La versión de Bolaños Geyer es la siguiente: "Al preguntársele que quién le ha auxiliado para la expedición, Walker contesta que varias personas de Estados Unidos afiliadas al partido político "Derechos de los Estados del Sur" al que pertenecen cientos de miles de personas. Dice que, hablando en general, dicho partido tiene los mismos fines que la Constitución impresa de la "Gran Logia Estrella Roja", encontrada por las autoridades entre sus papeles". Bolaños Geyer, William Walker, 387. 
Roja de Estados Unidos ${ }^{64}$. En The Milne Papers, se reproduce el preámbulo de dicho documento:

Para proteger, perpetuar y expandir la institución de la "esclavitud negra", como la base del más sólido, durable y benéfico sistema social e industrial que existe en el mundo.

Para formar opinión a favor de tal institución, y hacer eficaz esa opinión como un poder moral, político y aun físico.

Finalmente, para fortalecer una causa justa con todos los elementos de fuerza y mantener el derecho a cualquier riesgo, como la mejor prueba que los hombres pueden ofrecer acerca de que merecen gozar sus beneficios.

Los Amigos del Sur y sus instituciones se han organizado en una liga y han adoptado las siguientes: Reglas ${ }^{65}$.

De acuerdo con Bolaños Geyer, la Gran Logia Suprema de la Liga de la Estrella Roja se organizó en Nueva Orleans en abril de $1860^{66}$. Esto es, dos meses antes de que Walker zarpara el nueve de junio de 1860 de Nueva Orleans con destino a Honduras, lo que quizá no sea mera casualidad, como tampoco que el Gran Secretario Supremo de la Logia fuese Thomas F. Fisher, "el propagador Know-Nothing de la esclavitud en California que le ayudó a Walker en Nicaragua desde el comienzo"67.

Otros elementos sugieren alguna relación entre el símbolo de la estrella roja y la causa de Walker. En primer lugar, resulta notorio que la Gran Logia Suprema de la Liga de la Estrella Roja incorporó en su nombre un símbolo que Walker y su movimiento filibustero ya habían utilizado con anterioridad a 1860 y entre cuyos antecedentes figuran la

\footnotetext{
${ }^{64}$ El periódico filibustero The New Orleans Delta, reportó que según informes de miembros de la expedición de Walker a Honduras, "todos los oficiales y hombres del grupo de Walker fueron examinados en busca de papeles que pudieran usarse para condenarlos". Reproducido en The Gazette and Democrat, "The Death of Gen. Walker", 4 de octubre de 1860, 3.

${ }^{65}$ John Beeler, ed., The Milne Papers: The Papers of Admiral of the Fleet Sir Alexander Milne, Bt. K.C.B. (1806-1896), vol. II, The Royal Navy and the Outbreak of the American Civil War, 1860-1862 (Farnham y Burlington: Ashgate Publishing Limited, 2015), 98.

${ }^{66}$ Bolaños Geyer, William Walker, 429.

${ }^{67}$ Otros colaboradores de Walker del movimiento Know Nothing fueron E. J. C. Kewen, Parker H. French y Birkett D. Fry. Bolaños Geyer, William Walker, 429. Véase también William Walker, The War in Nicaragua (Mobile: S. H. Goetzel \& Co., 1860), 25-27.

French, por ejemplo, fue Ministro de Hacienda de Nicaragua y en 1855 fue elegido por Walker como representante del Gobierno de Nicaragua ante Estados Unidos, en condición de Enviado Extraordinario y Ministro Plenipotenciario. "Mr. Wheeler, Ministro americano en Nicaragua, tan pronto como se inauguró el Gobierno de don Patricio Rivas se apresuró a reconocerlo oficialmente", pero finalmente la administración de Pierce se negó a recibir a French y en diciembre de ese mismo año este fue arrestado en Nueva York acusado de "estar haciendo enganches de filibusteros para Nicaragua, aunque se le puso en libertad al poco tiempo". José. D. Gámez, Historia de Nicaragua desde los tiempos prehistóricos hasta 1860, en sus relaciones con España, México y Centroamérica (Managua: Tipografía de El País, 1889), 625-626. De Bow's Review, "Nicaragua and the Filibusters", 20, no. 6 (1856): 689.

Sobre la ayuda de los Know Nothing a Walker véase Bolaños Geyer, William Walker, 188-208
} 
bandera de la estrella solitaria de Texas y la de Cuba ${ }^{68}$. Esta última incluso fue izada en Nicaragua el 12 de julio de 1856 en la plaza de Granada, día de la toma de posesión de Walker como presidente ${ }^{69}$. Dos estrellas rojas también aparecían en la bandera filibustera de la "República de Sonora y Baja California". Adicionalmente, uno de los cuerpos del ejército de Walker en Nicaragua se denominaba la Guardia de la Estrella Roja (Red Star Guard $)^{70}$.

El símbolo de la estrella roja fue un elemento de la bandera que en setiembre de 1856 Walker adoptó para Nicaragua. Esta constaba de tres franjas. La central tenía el doble de ancho que las otras, de color blanco y mostraba una estrella roja de cinco puntas en su centro. Las otras dos franjas eran azules ${ }^{71}$.

Los filibusteros consideraron esa bandera como la de Nicaragua. Así, por ejemplo, varios periódicos estadounidenses reprodujeron la versión del soldado filibustero $\mathrm{E}$. $\mathrm{H}$. McDonald, acerca de la retirada de las tropas costarricenses de La Trinidad, un episodio de la segunda fase de la Campaña Nacional ${ }^{72}$. Según McDonald, el 14 de febrero de 1857 “el capitán de Brissot y un voluntario al que llamaban Kentuck fueron en una canoa, arrancaron la bandera de Costa Rica y enarbolaron 'la Estrella Solitaria de Nicaragua",73. A esta bandera, el Primer Batallón de Rifleros agregó el lema "Five or None": los cinco o

\footnotetext{
${ }^{68}$ La bandera de Cuba se inspirada en la de Texas y fue bosquejada por el filibustero Narciso López. Un ejemplar de la bandera cubana de 1856 se conserva en el Museo Histórico Juan Santamaría (Alajuela, Costa Rica), tomada por José V. Zavala en la ciudad de Granada (Nicaragua) el 12 de octubre de 1856, de la propia casa de Walker.

69 “"El sábado 12 de julio, Walker sustituyó a Ferrer en la presidencia.

Se procuró ese día que todas las ceremonias previas a la toma de posesión fueran solemnes y pomposas.

Con tal objeto se publicaron programas que indicaban el orden y la clase de ceremonias que se iban a verificar.

En el lado oeste de la plaza se levantó una plataforma adornada con las banderas de los Estados Unidos, Francia, Nicaragua y la Estrella Solitaria de Cuba". Montúfar, Reseña histórica de Centroamérica, 490.

${ }^{70}$ Walker, The War in Nicaragua, 391, 394, 397, 400. Scroggs, Filibusters and Financiers, 292. Montúfar, Reseña histórica de Centroamérica, 909. James Carson Jamison, With Walker in Nicaragua or Reminiscences of an Officer of the American Phalanx (Columbia, Missouri: E. W. Stephens Publishing Company, 1909), 150 .

${ }^{71}$ James Jeffrey Roche, The Story of the Filibusters (Londres y Nueva York: T. Fisher Unwin y Macmillan \& Co., 1891), 138. Véase también Walker, The War in Nicaragua, 318 y 321. Scroggs, Filibusters and Financiers, 245. Montúfar, Reseña histórica de Centroamérica, 696, 698, 699 y 984. Moore, "Pierre Soulé", 220.

${ }^{72}$ Véase sobre este episodio: Rafael Obregón Loría, Costa Rica y la Guerra del 56 (La Campaña del Tránsito) 1856-1857 (San José: Editorial Costa Rica, 1976), 189-193.

${ }^{73}$ Entre ellos, Daily Advocate, "Late and Important from Nicaragua", 14 de marzo de 1857, 2; The New York Herald, "Important from Nicaragua", 14 de marzo de 1857, 1; The New York Daily Tribune, "Later from Nicaragua", 14 de marzo de 1857, 7; The New York Times, "Important from Nicaragua", 14 de marzo de 1857, 1; The Daily Dispatch, "The Battles of Nicaragua. Further Particulars", 16 de marzo de 1857,2 y Cooper's Clarksburg Register, "Further from Nicaragua", 27 de marzo de 1857, 2.
} 
ninguno, una clara alusión a las aspiraciones filibusteras de domeñar las cinco repúblicas centroamericanas, representadas por las cinco puntas de la estrella roja ${ }^{74}$.

En la prensa estadounidense se ligaba el símbolo de la estrella solitaria a la figura de Walker. The Prairie News del 6 de mayo de 1858 publicó una carta de un autor identificado solamente como R, quien afirmaba:

He visto y conversado con el general Walker. Todas las imágenes que alguna vez he visto o descripciones que he escuchado de él, aunque de ninguna manera eran lisonjeras, aun así, lo favorecían. Es un hombre que parece ser muy silencioso, ecuánime y caballeroso. No hay nada en su apariencia que indique que es el general Walker o alguien con el genio del general Walker, excepto por sus ojos. La manera en que sus párpados cuelgan impartiría una expresión somnolienta a su semblante, de no ser por la fogosa brillantez de sus "ojos grises azulados". Sus labios son delgados y creo que las comisuras de su boca cuelgan. Dice que retornará a Nicaragua este verano. Bravo por la estrella solitaria de Nicaragua, y tres hurras por el glorioso Walker ${ }^{75}$.

Y el capitán filibustero William Hix Clowes (1789-1871) expresaba en The New York Herald en diciembre de 1857, con optimismo, aunque con poco sentido de la realidad: “... con confianza predecimos que en veinte días, William Walker, el gran pionero de la civilización estadounidense, habrá puesto su tienda frente a los muros de aquella más antigua capital de Costa Rica, y que diez días después de eso la Estrella Solitaria de Nicaragua estará ondeando en triunfo sobre el tradicional palacio de los Mora"76.

Sin embargo, también debe considerarse que el símbolo de la estrella roja ha sido ampliamente usado en muchas otras organizaciones "secretas", no relacionadas con Walker o el filibusterismo.

\section{Conclusiones}

Como se sugiere a lo largo del texto, el entramado de las conexiones de Walker era muy complejo y, en no pocas ocasiones, las relaciones que se le atribuían con sociedades secretas eran ficticias.

Durante la Guerra de Secesión, los unionistas, en su afán de atacar a los grupos de Copperheads, crearon la ficción de los K.G.C. como una fuerza bien organizada y extendida que retomaba los principios de acción de las Southern Rights Associations y las

\footnotetext{
${ }^{74}$ Roche, The Story of the Filibusters, 117. Richard Harding Davis, Real Soldiers of Fortune (Nueva York: Charles Scribner's Sons, 1914), 176. Scroggs, Filibusters and Financiers, 245.

${ }^{75}$ The Prairie News, "Editorial Correspondence", 6 de mayo de 1858, 2.

${ }^{76}$ William Hix Clowes, "What One of Walker's Officers Thinks of Him and His Cause", The New York Herald, 14 de diciembre de 1857, 2.
} 
ideas secesionistas que existían en el Sur. Ligaron, además, la figura de Walker con los K.G.C., para acusar a los Copperheads de esclavistas, filibusteros y secesionistas. Fundada a mediados de 1859, la Orden de los K.G.C. no tuvo acción militar alguna por falta de recursos y por la indolencia de su líder G. W. Bickley. Es improbable que William Walker haya sido miembro de los K.G.C. o que hubiera recibido su ayuda.

Diversas fuentes ligan a los K.G.C. con la Orden de la Estrella Solitaria: esta había sido la antecesora o una rama de aquella, o bien, ambas se habían fusionado. Pero esta perspectiva es errónea. Como ha expuesto ampliamente Klement, los K.G.C. fueron en gran medida una invención que atendía a los intereses personales de Bickley, primero, y a los de los unionistas durante la Guerra de Secesión, después.

Walker no fue miembro de la orden de los K.G.C. ni recibió su apoyo financiero o militar. En cambio, sí recibió apoyo de Soulé y quizá de otras personas que fueron miembros o participaron en los proyectos expansionistas de la Orden de la Estrella Solitaria respecto de Cuba. En todo caso, tales proyectos fueron un antecedente de la invasión a Nicaragua por parte de Walker y algunos de sus más cercanos colaboradores habían participado previamente en las incursiones filibusteras a Cuba.

Algunos miembros del movimiento Know Nothing apoyaron a Walker desde el inicio de su carrera filibustera en Baja California y Sonora. Los fundamentos ideológicos de ese movimiento eran en gran medida compatibles con el expansionismo y racismo del proyecto de Walker. Si atendemos a las palabras del propio Walker y a la afirmación de Bolaños Geyer ${ }^{77}$ de que Thomas F. Fisher -uno de los leales acólitos de Walker- era el Gran Secretario Supremo de la Gran Logia Suprema de la Liga de la Estrella Roja, la hipótesis de que esta organización brindó ayuda al proyecto de la invasión de Roatán resulta plausible, pero debe ser examinada más ampliamente.

\section{Fuentes}

Clowes, William Hix. "What One of Walker's Officers Thinks of Him and His Cause". The New York Herald. 14 de diciembre de 1857.

Concha, José de la. Memoria dirigida al Excmo. Sr. don Francisco Serrano y Domínguez.

Madrid: Imprenta de La Reforma, 1867.

Cooper's Clarksburg Register. "Further from Nicaragua". 27 de marzo de 1857.

Daily Advocate. "Late and Important from Nicaragua". 14 de marzo de 1857.

Daily Alta California. "Nicaragua Matters". 16 de enero de 1857.

Daily Alta California. "The Meeting in New York on Saturday Night". 16 de enero de 1857.

De Bow's Review. "Nicaragua and the Filibusters". 20, no. 6 (1856): 670-692.

\footnotetext{
${ }^{77}$ Bolaños Geyer, William Walker.
} 
Diario de la Marina, "Fusilamiento de Walker", 26 de setiembre de 1860.

Diario de la Marina. 7 de agosto de 1860.

Diario de la Marina. 10 de agosto de 1860.

Frank Leslie's Illustrated Newspaper. "Grand Exposure of the Ceremonies of the Sons of Malta”. IX, no. 219 (1860): 161, 162, 169, 170.

Green Mountain Freeman. "Washington Matters". 28 de octubre de 1858.

Greely, Horace. The American Conflict: A History of the Great Rebellion in the United States of America, 1860-'64. Vol. 1. Chicago: Geo. \& C. W. Sherwood, 1865.

Hiatt, James M. An Authentic Exposition of the "K. G. C." "Knights of the Golden Circle"; Or, A History of Secession from 1834 to 1861. Indianápolis: C. O. Perrine Publisher, 1861.

Jamison, James Carson. With Walker in Nicaragua or Reminiscences of an Officer of the American Phalanx. Columbia, Missouri: E. W. Stephens Publishing Company, 1909.

Lagerstedt, Albert. "The Political Career of William Walker". Tesis de Maestría, Universidad de California, 1913.

Nashville Union and American. "The Movements and New Programme of the Filibusters". 24 de noviembre de 1858.

O’Sullivan, John. “Annexation”. United States Magazine and Democratic Review 17, no. 85 (1845): 5-10.

Southern Sentinel. "Reinforcements for Walker". 10 de mayo de 1856.

Syphax. "Louisiana Correspondence". New Orleans Daily Crescent. 11 de diciembre de 1858.

The Burlington Free Press. 29 de octubre de 1858.

The Daily Dispatch. "The Battles of Nicaragua. Further Particulars". 16 de marzo de 1857.

The Gazette and Democrat. "The Death of Gen. Walker". 4 de octubre de 1860.

The New York Daily Tribune. "K.G.C.". 13 de junio de 1859.

The New York Daily Tribune. "Later from Nicaragua". 14 de marzo de 1857.

The New York Herald. "Conspiracy of Lopez in Cuba". 10 de febrero de 1858.

The New York Herald. "First Attempt of Lopez from This Country". 10 de febrero de 1858.

The New York Herald. "Last Expedition and Death of Lopez". 10 de febrero de 1858.

The New York Herald. "Important from Nicaragua". 14 de marzo de 1857.

The New York Herald. "The Hon. Pierre Soulé and the Question of the Central America". 3 de mayo de 1856.

The New York Times. "Hon. Pierre Soulé Hacienda”. 30 de marzo de 1857.

The New York Times. "Important from Nicaragua". 14 de marzo de 1857.

The New York Times. "Masquerade of the Sons of Malta". 12 de octubre de 1859.

The New York Times. "The Knights of the Golden Circle". 30 de agosto de 1861.

The Prairie News, "Editorial Correspondence”. 6 de mayo de 1858. 
The Prairie News. "Parson Brownlow on the Walker Developments". 11 de marzo de 1858.

The Spectator. "The Knights of the Golden Circle". 17 de agosto de 1861.

The United States Democratic Review. "The Order of the Lone Star". 32, no.1 (1853): 8085.

The United States National Union Club. K.G.C.: An Authentic Exposition of the Origin, Objects, and Secret Work of the Organization Known as the Knights of the Golden Circle (1862 [citado el 8 de mayo de 2016]): disponible en https://books.google.co.cr/books?id=LPwIta1NyLgC\&pg=PA5\&lpg=PA5\&dq=kn ights + of + the + columbian + star\&source $=$ bl\&ots $=$ QkKieCOxSO\&sig $=J 1 x A 6 u s U 0 U b$ xrW4KBNHuxI7B86U\&hl=es\&sa $=$ X\&redir_esc $=\mathrm{y} \# \mathrm{v}=$ onepage $\& \mathrm{q}=$ knights $\% 20 \mathrm{of}$ $\% 20$ the $\% 20$ columbian $\% 20$ star $\& \mathrm{f}=$ false

The Working Man's Friend and Family Instructor III, no. 53. "The Order of the Lone Star" (1852): 10-11.

The Yazoo Democrat. "I.O.S.M.". 7 de abril de 1860.

The Yazoo Democrat. 7 de abril de 1860.

Tulane University of Louisiana. An Inventory of the Manuscript Collections of the Department of Middle American Research. No. 1 Callender I. Fayssoux Collection of William Walker Papers. New Orleans: Tulane University of Louisiana, 1937.

Walker, William. The War in Nicaragua. Mobile: S. H. Goetzel \& Co., 1860.

Welles, William W. Walker's Expedition to Nicaragua: A History of the Central America War. Nueva York: Stringer and Townsend, 1856.

\section{Bibliografía}

Beeler, John, ed. The Milne Papers: The Papers of Admiral of the Fleet Sir Alexander Milne, Bt. K.C.B. (1806-1896). Vol. II: The Royal Navy and the Outbreak of the American Civil War, 1860-1862. Farnham y Burlington: Ashgate Publishing Limited, 2015.

Bolaños Geyer, Alejandro. William Walker, el Predestinado de los Ojos Grises. San Charles, Missouri: impresión privada, 1995.

Boman, Patrick. Boulevard de la flibuste: Nicaragua 1850-1860. París: Ginkgo éditeur, 2007.

Brown, Charles H. Agents of Manifest Destiny: The Lives and Times of the Filibusters. Chapel Hill: University of North Carolina Press, 1980.

Cáceres Lara, Víctor. "La aventura postrera de William Walker en Honduras". Revista Conservadora 10, no. 52 (1965): 44-53. 
Chaffin, Tom. “'Sons of Washington': Narciso López, Filibustering, and U.S. Nationalism, 1848-1851". Journal of the Early Republic 15, no. 1 (1995): 79-108.

Claiborne, J. F. H. Life and Correspondence of John A. Quitman. Vol. II. Nueva York: Harper \& Brother, 1860.

Courtemanche, Regis A. "The Royal Navy and the End of William Walker". The Historian 30, no. 3 (1968): 350-365.

Crenshaw, Ollinger. "The Knights of the Golden Circle: The Career of George Bickley". The American Historical Review 47, no. 1 (1941): 23-50.

Dahlstrom, James. "America, the Forbidden Fruit: Anti-American Sentiment in 'Robbery under Arms"”. Antipodes 25, no. 2 (2011): 145-150.

Davis, Richard Harding. Real Soldiers of Fortune. New York: Charles Scribner's Sons, 1914.

Dollero, Adolfo. Cultura cubana (la provincia de Pinar del Río y su evolución). La Habana: Imprenta Seoane y Fernández, 1921.

Etchenson, Nicole. Bleeding Kansas: Contested Liberty in the Civil War Era. Lawrence: University Press of Kansas, 2004.

Fornell, Earl W. "Texans and Filibusters in the 1850's". The Southwestern Historical Quarterly 59, no. 4 (1956): 411-428.

Franklin, John Hope. The Militant South 1800-1861. Urbana y Chicago: University of Illinois Press, 2002.

Gámez, José D. Historia de Nicaragua desde los tiempos prehistóricos hasta 1860, en sus relaciones con España, México y Centroamérica. Managua: Tipografía de El País, 1889.

Hixson, Walter L. American Foreign Relations. A Diplomatic History. Nueva York y Londres: Routledge, 2016.

Jones, Lewis P. "Ambrosio José Gonzales, a Cuban Patriot in Carolina". The South Carolina Historical Magazine 56, no. 2 (1955): 67-76.

Johnson, Samuel A. "The Genesis of the New England Emigrant Aid Company". The New England Quarterly 3, no. 1 (1930): 95-122.

Keehn, David C. Knights of the Golden Circle: Secret Empire, Southern Secession, Civil War. Baton Rouge: Louisiana State University Press, 2013.

Klement, Frank L. "Copperhead Secret Societies: In Illinois during the Civil War”. Journal of the Illinois State Historical Society 48, no. 2 (1955): 152-180.

Klement, Frank L. "Carrington and the Golden Circle Legend in Indiana during the Civil War". Indiana Magazine of History 61, no. 1 (1965): 31-52.

Klement, Frank L. Dark Lanterns: Secret Political Societies, Conspiracies, and Treason Trials in the Civil War. Baton Rouge: Louisiana University Press, 1989.

Klement, Frank L. "Catholics as Copperheads during the Civil War". The Catholic Historical Review 80, no. 1 (1994): 36-57. 
Marrero, Leví. Cuba: sociedad y economía. Tomo VII, Azúcar, Ilustración y conciencia. Madrid: Editorial Playor S. A., n.d.

Mayes Huete, Guillermo. Campaña nacional centroamericana contra los filibusteros en Nicaragua, 1856-1956. Tegucigalpa: Ministerio de Educación Pública, 1956.

Montúfar, Lorenzo. Reseña histórica de Centroamérica. Tomo VII. Guatemala: Tipografía La Unión, 1887.

Moore, J. Preston. "Pierre Soulé: Southern Expansionist and Promoter". The Journal of Southern History 21, no. 2 (1995): 203-223.

Obregón Loría, Rafael. Costa Rica y la Guerra del 56 (La Campaña del Tránsito) 18561857. San José: Editorial Costa Rica, 1976.

Portell Vilá, Herminio. Narciso López y su época (1848-1850). La Habana: Compañía Editora O'Reilly, 1952.

Rauch, Basil. American Interest in Cuba: 1848-1855. Nueva York: Columbia University Press, 1948.

Roche, James Jeffrey. The Story of the Filibusters. Londres y Nueva York: T. Fisher Unwin y Macmillan \& Co., 1891.

Rosengarten Jr., Frederic. William Walker y el ocaso del filibusterismo. Tegucigalpa: Guaymuras, 2002.

Scroggs, William O. Filibusters and Financiers: The Story of William Walker and His Associates. New York: The Macmillan Company, 1916.

Stevens, Albert C., ed. The Cyclopedia of Fraternities. Nueva York: Hamilton Printing \& Publishing Co., 1899.

White, Laura A. "The United States in the 1850's as Seen by British Consuls". The Mississippi Valley Historical Review 19, no. 4 (1933): 509-536. 